\title{
Green wet chemical route to synthesize capped CdSe quantum dots
}

\author{
A OUDHIA and P BICHPURIA* \\ Department of Physics, Government VYT PG Autonomous College, Durg 491 001, India
}

MS received 25 November 2012; revised 13 February 2013

\begin{abstract}
In the present work, we report green synthesis of tartaric acid (TA) and triethanolamine (TEA) capped cadmium selenide quantum dots (CdSe QDs) employing chemical bath deposition (CBD) method. The mechanism of capping using non-toxic binary capping agents is also discussed. Stable QDs of various sizes were obtained by varying $\mathrm{pH}$ of the bath. The structural, morphological and spectroscopic characterization of the as-prepared samples by XRD, SEM, optical absorption and photoluminescence (PL) is also reported.
\end{abstract}

Keywords. CdSe quantum dots; chemical bath deposition; capping; green chemistry; nanomaterials.

\section{Introduction}

Semiconductor QDs have wide range of applications such as in solar cells, laser source, and electroluminescent devices (Anpo et al 1997; Kwon et al 2001). The modified morphology and molecular design of these optical materials exhibit highly efficient luminescence (Friend Prasad et al 1999). As an alternative to dye sensitizers in DSSC, QDs made of CdS, $\mathrm{PbS}, \mathrm{CdSe}$, InAs and InP (Cho et al 1994; Li et al 2004; De Angelis et al 2005; Ferrere et al 2006; Chang et al 2007; Chen et al 2008) have been explored to function as the sensitizers in the so-called QD-sensitized $\mathrm{TiO}_{2}$ or $\mathrm{ZnO}$ based solar cells because of their large extinction coefficient and proper energy level for effective electron transfer to the conduction band upon visible light irradiation (Gratzel 2003; Jiang et al 2007).

Although QDs have a unique advantage over organic dyes as the alternative sensitizers for solar cell, their power conversion efficiency is still very low. The poor performance of QDSSCs can be primarily attributed to the difficulty in obtaining smoothly covered QD layer linked to the buffer layer of the solar cells. The use of proper capping agent can be helpful in solving this problem. Recently, new safer methods have been developed for the synthesis of high quality CdSe QDs without using toxic TOP solvent (Klimov and Schaller 2004; Chang and Lee 2007; Nozik 2008). Furthermore, the process can be operated under open atmosphere (Chang and Lee 2007). Here, we report an improved method of preparation of CdSe QDs capped by TA and TEA. The focus is on the green synthesis method to prepare stable CdSe QDs and study the effect of quantum confinement on their optical properties. CBD method is employed for a low cost and green synthesis of QDs. The effect of variation in $\mathrm{pH}$ on the growth mechanism, structure and morphology of CdSe QDs is presented in this paper.

\footnotetext{
*Author for correspondence (pbichpuria@gmail.com)
}

\section{Experimental}

\subsection{Film preparation}

CdSe QDs were grown on the cleaned glass substrates by $\mathrm{CBD}$ method. Sodium seleno sulfate $\left(\mathrm{Na}_{2} \mathrm{SeSO}_{3}\right)$ and cadmium acetate $(\mathrm{CdAc})$ was taken as the sources for selenium and cadmium, respectively. TA and TEA were used as capping agents following the general method described by Chougule et al (2004). $\mathrm{Na}_{2} \mathrm{SeSO}_{3}$ solution was prepared by dissolving $50.0 \mathrm{~g}$ of sodium sulfite in $250 \mathrm{~mL}$ of deionized water at room temperature (RT) until the solution became clear. $2.50 \mathrm{~g}$ of elemental selenium was added to the solution, which was refluxed at $65^{\circ} \mathrm{C}$ for $6.5 \mathrm{~h}$, cooled at RT and left overnight to settle down. For preparation of CdAc solution $13.33 \mathrm{~g}$ of CdAc was dissolved in $250 \mathrm{~mL}$ of deionized water at RT under constant stirring to get a clear solution. The solution was monitored with a $\mathrm{pH}$ probe (E1 Products 131 E) throughout the preparation. Aqueous solution of $1 \mathrm{M}$ TA was added to $\mathrm{CdAc}$ solution until it reached a $\mathrm{pH}$ of 5. TEA was added to $\mathrm{CdAc}+\mathrm{TA}$ solution until the observed $\mathrm{pH}$ increased to 8. Stock solutions of $\mathrm{Na}_{2} \mathrm{SeSO}_{3}$ and $\mathrm{CdAc}+\mathrm{TA}+\mathrm{TEA}$ were mixed in the ratio $1: 1$ and were kept in bath at $65{ }^{\circ} \mathrm{C}$ for $1 \mathrm{~h}$. In order to control the $\mathrm{pH}$ further, appropriate amount of $5 \mathrm{M} \mathrm{NaOH}$ was added. All the high purity reagents were purchased from Merck and were used as obtained. The capped CdSe QD sol was left overnight, decanted and washed 3-4 times by ethanol and double-distilled water before use. The sol was deposited as thin films on the pre-cleaned glass slides with the help of doctor's blade and dried in air.

\section{Results and discussion}

\subsection{Capping mechanism}

CdSe QDs were capped with non-toxic TEA and TA instead of TOPO in ambient atmosphere using a green chemistry 
a<smiles>O=C(O)C(O)C(O)C(=O)O</smiles>

b

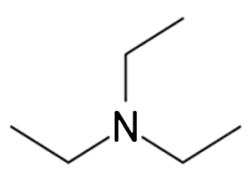

C

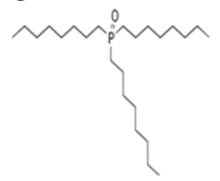

Figure 1. Structural formula of (a) TA, (b) TEA and (c) TOPO.

approach. By comparing the mechanism to that with TOPO capped CdSe, we shall show that TA and TEA helps through fast ligand exchange with the bifunctional surface linker, this increases QDs light harvesting efficiency. Figure 1 shows TA, TEA and TOPO molecular structures, with zig-zag chain and tetrahedron configurations respectively.

The mechanism of binary capping with TEA and TA can be explained on the basis of well-known hard and soft acids and bases theory (Pearson 1963). The hard-hard or softsoft molecules or ions form a strong binding, owing to the polarizability of electron cloud. $\mathrm{Cd}^{2+}$ and $\mathrm{Se}^{2-}$ ions are classified as soft ions having stronger interaction with soft "- $\mathrm{NH}_{2}$ " from TEA than the hard "- $\mathrm{COOH"} \mathrm{from} \mathrm{TA.}$ Although TA molecules with linear carbon-carbon structure easily forms a denser cover layer on the surface of CdSe, preventing other capping agents from approaching $\mathrm{CdSe}$ QDs, the weak bonding between carboxyl functional group "-COOH" from TA and CdSe weaken the capping effect. During the period of dynamic dissociation and association of ligand, TEA molecule can form rather strong bonding with CdSe involving soft " $-\mathrm{NH}_{2}$ " from TEA and soft $\mathrm{Cd}^{2+}$ or $\mathrm{Se}^{2-}$ ions. The different strengths of bonding enhance the ligand exchange between TA and TEA. After TA and TEA ligand exchange, TEA links QD to the buffer layer in solar cell by an amine " $-\mathrm{NH}_{2}$ " and carboxyl group "-COOH", respectively. Smaller seed particles absorbed by TEA surrounds CdSe QDs, which prevents further uncontrolled growth via ripening. The use of TEA as a functionalizing agent can be attributed to steric repulsion between TEA chains adsorbed on nanoparticle surfaces, similar conclusions were drawn for PEG capped gold particles (Luo et al 2005). Hence, the modification of CdSe QD capping can play a key role to improve CdSe loading in QD sensitized solar cells. On the other hand, the structure of TOPO molecule results in the repellence toward foreign molecules such as TEA. Moreover, the soft "PO" functional group in TOPO interacts strongly with CdSe. Hence, the usage of TOPO as capping agent will result in a low rate of ligand exchange making TOPO capped CdSe QDs unsuitable for solar cell application.

\subsection{Optical studies}

The samples prepared with different $\mathrm{pH}$ show strikingly different colour under white light. At $\mathrm{pH} 10 \cdot 5$, the precipitation of yellow CdSe QDs occurred easily. At pH 11.5, a transparent colloidal solution was obtained which was stable for more than one month, precipitation by adding $\mathrm{NaOH}$ resulted in bright orange QDs. Similarly at pH 12.5, we got a stable homogeneous red colloidal solution and red QDs after precipitation.

Figure 2 shows variations in PL and optical absorption spectra of CdSe QDs at $R T$ with respect to the solution $\mathrm{pH}$. PL spectra were measured using Perkin Elmer LS55 fluorescence spectrophotometer, whereas the optical absorption was investigated using UV-Vis spectrophotometer (Varian Carry 50 BIO). Sample shows absorbance onset at $\sim 700 \mathrm{~nm}$. The long absorption tails are observed due to light scattering at high concentration of nanoparticles. Three distinct absorption peaks are present in the visible region corresponding to the particle sizes obtained at different $\mathrm{pH}$. The shift of absorption to shorter wavelength with the decrease in the particle size implies the quantum confinement effect in these particles (Klimov and Schaller 2004). By using hyperbolic band model under effective mass approximation, we identified the size of these QDs from the excitonic transition wavelength 575,550 and $500 \mathrm{~nm}$, as $3 \cdot 12,2.8$ and $2.32 \mathrm{~nm}$, respectively, which are less than Bohr radii of CdSe, showing strong quantum confinement (Guo et al 2003). PL spectra in figure 2 shows blue shifting of the emission peaks with the decreasing size of CdSe QDs. PL peak was observed at $611 \mathrm{~nm}$ for $\mathrm{pH} 10 \cdot 5$, at $576 \mathrm{~nm}$ for $\mathrm{pH} 11.5$ and at $528 \mathrm{~nm}$ for $\mathrm{pH} 12 \cdot 5$. The defect levels like shallow or deep trap emissive states disappear at higher $\mathrm{pH}$ as the particles enter into the quantum confinement regime and so PL emission of QDs is very specific and narrow as they can only emit fluorescence energy from the lowest energy level in the conductance band to the highest energy level in the valence band (Galli et al 2002; Bailey and Nie 2003). However, the broadening of peaks can be attributed to phonon assisted absorption and emission.

\subsection{Effect of pH on morphology and structure of CdSe QDs}

Figure 3 shows SEM patterns (observed with ZEISS EVO MA 10) of thin films of CdSe QDs prepared with varying $\mathrm{pH}$ at a magnification of $\sim 5.00 \mathrm{k} \times$ res. These SEM patterns are composed of small nanosized grains with high yield and uniform deposition. Enhancement in the yield and uniformity is observed as the $\mathrm{pH}$ of the bath increases.

Figure 4 shows XRD pattern of CdSe QDs prepared at different $\mathrm{pH}$ observed with the help of Rigaku miniflex ${ }^{\circledR}$. The peaks located at $2 \theta=26.03,47.54$ and $56.37^{\circ}$ can be attributed to (111), (220) and (311) planes of the zincblend phase of CdSe. FWHM of the peaks show broadening with increasing alkalinity showing decrease in particle size at higher $\mathrm{pH}$. The particle sizes were calculated by Scherrer's formula and they are found to be 3.8 and $2.7 \mathrm{~nm}$, respectively for $\mathrm{pH} 10.5$ and 12.5 for the prominent peaks. The results are almost similar to that obtained by optical absorption studies. 

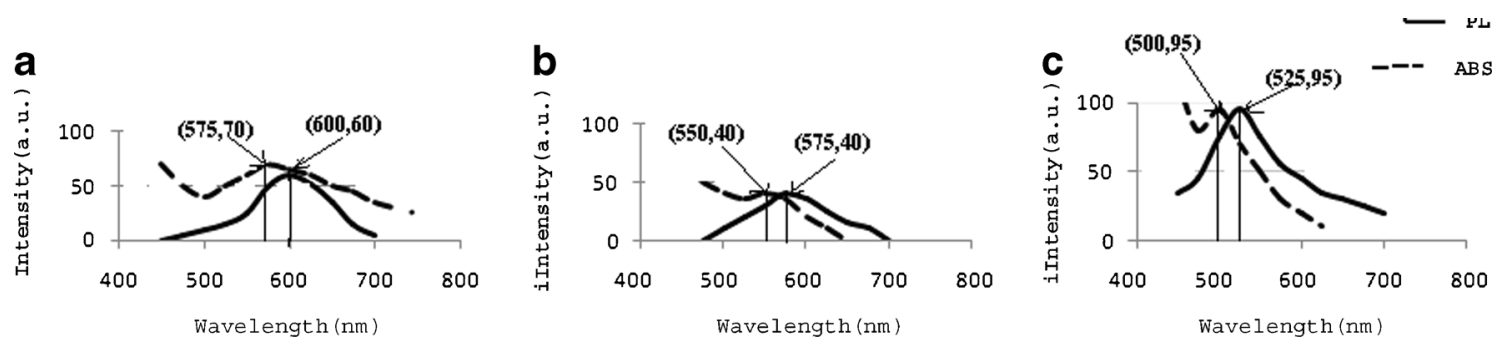

Figure 2. PL and optical absorption spectra of CdSe QDs showing blue shift and size dispersion with $\mathrm{pH}(\mathbf{a}) \mathrm{pH} 10 \cdot 5$ (b) $\mathrm{pH} 11.5$ and (c) $\mathrm{pH} 12.5$.

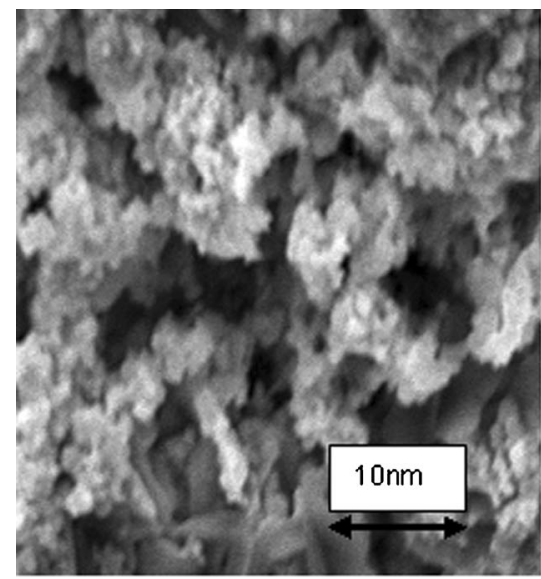

$10.5 \mathrm{pH}$

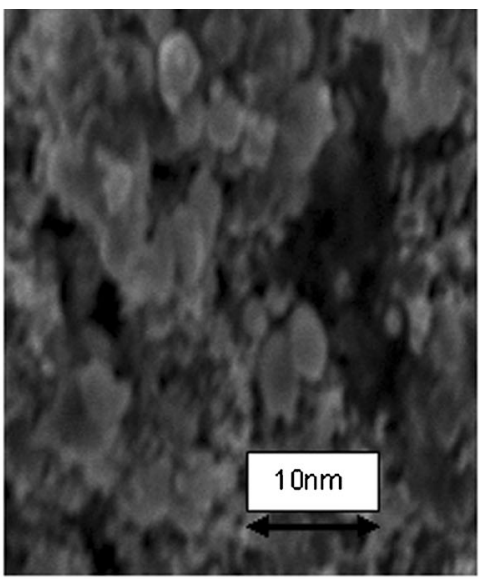

$11 \cdot 5 \mathrm{pH}$

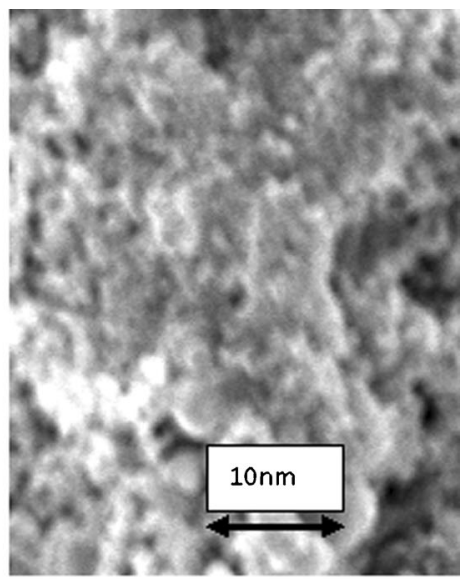

$12 \cdot 5 \mathrm{pH}$

Figure 3. SEM of CdSe QDs (a) $\mathrm{pH} 10 \cdot 5$ (b) $\mathrm{pH} 11.5$ and (c) $\mathrm{pH} 12.5$.
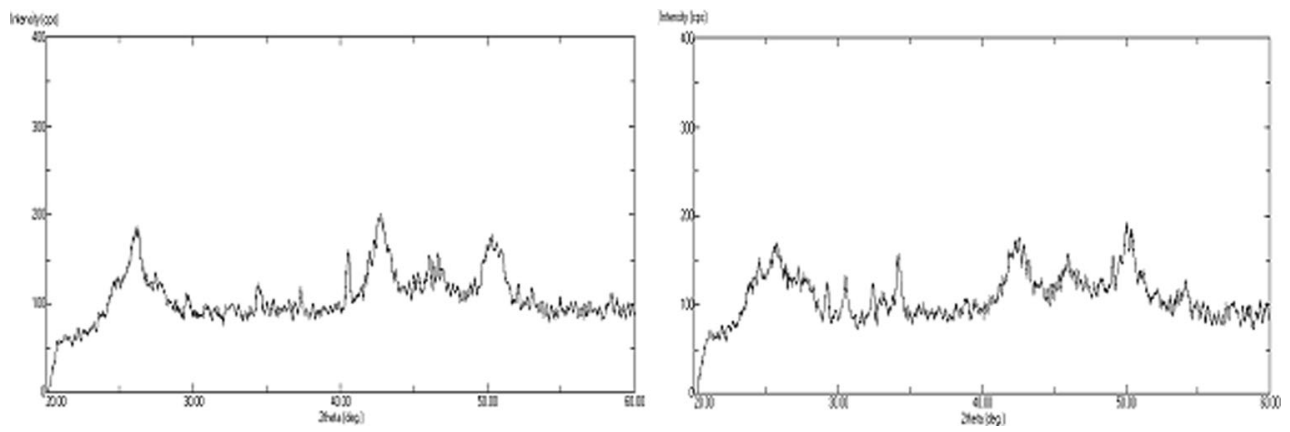

Figure 4. XRD pattern of CdSe QDs (a) $\mathrm{pH} 10 \cdot 5$ and (b) $\mathrm{pH} 12.5$.

\section{Conclusions}

In present work, a green chemistry approach was used successfully to prepare size controlled CdSe QDs capped with non-toxic TEA and TA instead of toxic TOPO. The addition of TEA not only stabilized the nanoparticle by steric repulsion and trapping of seeds, but also allowed controlled further growth of QDs, improving homogeneity in QDs size, shape and stability. The results explain formation mechanism of CdSe QDs synthesized in the absence of TOPO. The size controlled stable CdSe QDs were grown easily by varying
$\mathrm{pH}$ of the chemical bath in ambient atmosphere. The optical absorption and PL spectra give blue shift due to quantum confinement. SEM and XRD results confirm the zinc blend structure of extremely fine particles, showing decreasin particle size with increasing $\mathrm{pH}$.

\section{Acknowledgements}

The authors are grateful to the lab facilities made available at the Government VYT PG Autonomous College, Durg, GGU 
Central University, Bilaspur (CG) and Pt RSS University, Raipur (CG). We also gratefully acknowledge UGC, New Delhi for the research grant under MRP.

\section{References}

Anpo M, Yamashita H, Jung K T and Shu Y G 1997 Korean J. Chem. Engg. 14213

Bailey R E and Nie S M 2003 J. Am. Chem. Soc. 1257100

Chang C H and Lee Y L 2007 Appl. Phys. Lett. 91053503

Chang C H, Lin S C, Lee Y L, Shen Y J and Yang Y M 2007 Appl. Phys. Lett. 90143517

Chen P et al 2008 J. Phys. Chem. C112 11600

Cho H Y, Choi W C, Min S K and Yamaguchi M 1994 Appl. Phys. Lett. 641280

Chougule B K, Kale R B, Lokhande C D and Sartale S D 2004 Semicond. Sci. Technol. 19980
De Angelis F et al 2005 J. Am. Chem. Soc. 12716835

Ferrere S, Frank A J, Norman A, Nozik A J, Yu P R and Zhu K 2006 J. Phys. Chem. B110 25451

Friend Prasad P N, Lal M, Winiarz J G and Zhang L 1999 J. Am. Chem. Soc. 1215287

Galli G, Grossman J C, Pizzagalli L, Puzder A and Williamson A J 2002 Nanotechnology 1470

Gratzel M 2003 J. Photochem. Photobiol. C4 145

Guo W, Peng X, Qu L and Yu W W 2003 Chem. Mat. 152854

Jiang C Y, Kwong D L, Lo G Q, Sun X W and Wang J X 2007 Appl. Phys. Lett. 90263501

Klimov V I and Schaller R D 2004 Phys. Rev. Lett. 92186601

Kwon M H, Park O O and Park J H 2001 Korean J. Chem. Engg. 18 580

Li B, Li J W, Qiu Y and Wang L D 2004 Phys. Lett. 211391

Luo C, Wang Y, Zeng X, Zeng Y and Zhang Y 2005 J Coll. Interf. Sci. 288444

Nozik A 2008 J. Chem. Phys. Lett. 4573

Pearson R G 1963 J. Am. Chem. Soc. 853533 